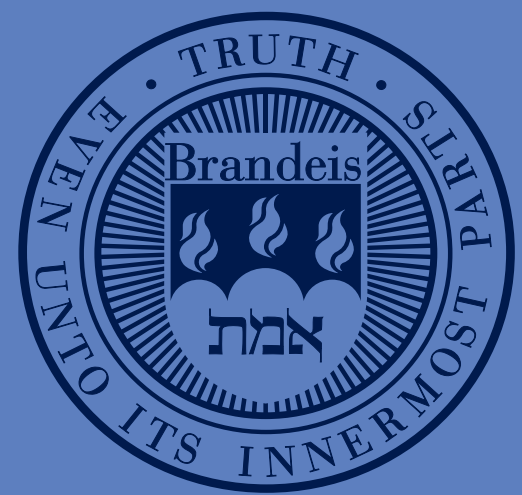

\title{
The Microstructure of Currency Markets
}

Carol Osler, Brandeis International Business School

Xuhang Wang, Graduate Student, Brandeis University

Working Paper Series 


\title{
The Microstructure of CURRency MARKetS
}

Carol Osler, Associate Professor and Program Director, Brandeis University

Xuhang Wang, Graduate Student, Brandeis University

Key words: Currency, foreign exchange, microstructure, price discovery, bid-ask spreads, liquidity.

\begin{abstract}
This paper describes the structure and microeconomics of the foreign exchange market. It begins by outlining the major participants and the instruments they trade, highlighting the vast institutional changes that accompanied the emergence of electronic trading since the 1990s. It then discusses how and why order flow drives exchange rates; the economics of liquidity provision; the price discovery process; and volatility.
\end{abstract}

This paper was prepared as a chapter of Survey of International Finance, Kent Baker \& Leigh Riddick, Eds. (Oxford University Press, forthcoming). 


\section{INTRODUCTION}

This chapter takes the reader beyond equities and bonds to focus on the microstructure of the foreign exchange market. This market dwarfs others: average daily foreign exchange trading exceeds $\$ 4.0$ trillion, according to the Bank for International Settlements (B.I.S., 2010), roughly 20 times daily US equity trading volume (CNN, 2012). Nonetheless, it has been less intensively studied than other markets, possibly because it emerged as a major focus of speculative activity somewhat belatedly.

Foreign currencies can be exchanged in almost every community of any significant size, though such trading is especially active in London, New York, Tokyo, Singapore, Hong Kong, and Sydney. Foreign currencies can also be traded at almost any time, since the market operates continuously 24 hours a day; there is even some trading on weekends. Trading activity follows the sun, picking up early in the morning in Sydney, Australia (22:00 GMT) and slowing down late in the day in New York City (19:00 GMT). Market liquidity rises and falls as foreign exchange traders enter and exit the market over the day. The intraday peak for both volume and volatility occurs around mid-day in London, when traders are active in both Europe and North America (see Figure 1).

\section{Currencies and Instruments}

The US dollar, long the dominant currency internationally, is still involved on one side of almost 85 percent of all trades (B.I.S., 2010). This is due not only to the size of the U.S. product and financial markets, but also to the dollar's traditional role as a "vehicle currency" between most non-dollar currencies. A trader seeking to exchange non-dollar currencies A and B must first sell his As for dollars and then sell his dollars for Bs. The dollar's share in overall trading has declined from 90 percent in 2001, presumably in response to the euro's emergence as the vehicle currency within Europe. The euro is now involved in 39 percent of spot currency trades (these shares add to 200 percent, rather than 100 percent, since each trade involves two currencies). The next most actively traded currencies are the Japanese yen (19 percent) and 
British pound (13 percent). In fifth place is the Australian dollar (8 percent), which recently overtook the Swiss franc (6 percent).

Emerging market currencies have been a major source of market growth over the past decade, with Asian currencies leading the way (Wooldridge and Tsuyuguchi, 2008). The Hong Kong dollar, Korean Won, and Singapore dollar now trade in amounts comparable to Scandinavian currencies and the Indian rupee is not far behind. Between 1998 and 2010, the top-ten Asian currencies' combined turnover rose from roughly $\$ 41$ billion to $\$ 338$ billion per day. The 19 percent annual growth is more than double the overall market's 8 percent average growth. The Russian and Brazilian currencies grew at a similarly rapid pace (B.I.S., 2010). Microstructure research concentrates on spot and forward currency trading, which typically accounts for roughly half of what has formally been identified as foreign exchange trading. Spot transactions, which settle in two days (except for the US and Canadian dollars, which settle in just one day), averaged $\$ 1.2$ trillion per day in April 2010. Forward transactions, which generally settle later than spot (though "inside forwards" settle more quickly), averaged $\$ 0.4$ trillion per day in April 2010. For developing countries, the emergence of an active forward foreign exchange market serves as a development milestone, since such markets require support from a liquid money market. In a survey of emerging markets, only 9 percent of respondents considered their forward foreign exchange markets to be developed, liquid, and deep, while 30 percent considered them to be undeveloped, illiquid, and shallow (CanalesKriljenko, 2004).

Foreign exchange swaps dominate the rest of the foreign exchange market, with daily turnover in 2010 of $\$ 1.6$ trillion. These instruments are analogous to repurchase agreements, insofar as they combine a spot transaction with a forward reversing transaction. They are used primarily by banks for overnight position management. Other foreign exchange instruments include currency swaps ( $\$ 0.04$ trillion daily) and options ( $\$ 0.2$ trillion daily). 
The foreign exchange market is far more lightly regulated than most equity or bond markets. Governments hesitate to regulate local trading practices because currency trading can take place anywhere and trading operations - which pay well and are environmentally clean can simply move elsewhere. Despite the absence of regulation, the foreign exchange market copes remarkably well with crises. On 11 September 2001, foreign exchange markets remained open even in New York City. Mende (2006), who analyzed how liquid currencies responded to this event, finds that standard relations among trading volume, volatility, and bid-ask spreads were sustained. The shock persisted merely a day or two.

\section{A Two-Tier Market}

The foreign exchange market is at core a two-tier market. In one, customers trade directly with their dealers; in the other, dealers trade with each other. This underlying market structure is similar to that of the U.S. Treasury and municipal bond markets but different from that of most equity markets.

The customer market is a "quote driven" or "over the counter" (OTC) market, in which most individuals or institutions needing foreign currency trade with specialized dealers. A customer first contacts a dealer to request current prices; the dealer provides two quotes, a lower price at which the dealer will buy the specified currency and a higher price at which the dealer will sell it; finally, the customer decides whether to buy, sell, or pass. Dealers normally base their quotes on those prevailing in the interdealer market. Since customer trading is not anonymous, dealers customize the bid-ask spread for each customer. Prices for a given currency pair are always expressed as units of the numerator currency per unit of the base currency, where the base currency is determined by market convention.

The rest of this section focuses more narrowly on the foreign exchange market's liquidity providers and demanders. 


\section{Liquidity Providers}

Dealers trade very actively among themselves. Though trades among dealers accounted for over half of all trading in the 1980s and 1990s, this fraction has declined to 39 percent. Meanwhile, overall trading has grown so rapidly that in absolute terms interdealer spot trading grew over 50 percent between 2007 and 2010. The most recent estimate indicates that interdealer trading exceeds $\$ 500$ billion per day (B.I.S., 2010).

Before electronic trading was introduced to the interdealer market, around 1990, about half of interdealer trades were handled by voice brokers, who take orders from individual banks and verbally announce them to other major banks. By the late 1990s two major electronic limit order markets, Electronic Broking Service (EBS) and Reuters, had come to dominate interdealer trading. In the major currency pairs these brokers largely eliminated voice brokers and also replaced most direct interdealer trades. Voice brokers are still important among relatively illiquid currencies and account for about 10 percent of overall interdealer trading.

Electronic trading naturally increased transparency in the interdealer market, as it became far easier for dealers to learn the market price at a given moment. Beyond that, however, electronic trading transformed the market's industrial organization. Each big bank now offers its customers a multitude of "single-bank trading platforms," with each platform tailored to a specific customer type (King et al., 2012). The most active customers can receive streaming prices and can trade at the click of a mouse; the least active customers can pre-specify an amount to trade at the market's daily fixing price. The massive investment in trading infrastructure required to develop and support these trading platforms introduced economies of scale. This, in turn, brought a dramatic increase in market concentration among dealers. The rise in concentration has naturally been most pronounced where electronic trading is most prevalent. Between 2007 and 2010, the number of banks accounting for 75 percent of turnover fell from 12 to 9 in the UK, from 10 to 7 in the US, from 9 to 8 in Japan, and from 3 to 2 in 
Switzerland. In France and Canada, which are not major trading centers, the number did not change, and in Denmark, Hong Kong, and Korea it even rose a bit (B.I.S., 2010).

The foreign exchange market's increased concentration has, in turn, brought a significant change in the way dealers manage inventory. Historically, dealers managed inventory via interdealer trades, since customer trades arrived relatively infrequently while interdealer trades are fast and inexpensive. At large banks the time between customer trades at large banks has fallen dramatically, however, due to the overall expansion of currency trading and to industry consolidation. In consequence, large dealers now typically "warehouse" inventory for the brief interval of time until they can lay it off on other customers. At large banks the rise in profits from internalized customer trades has helpfully offset a decline in speculative profits from interdealer trading.

Dealers have also changed the way they quote prices. Historically, dealers did not shade usually prices based on their inventory - lowering prices when inventory was high and vice versa - due to a reluctance to give other dealers information about their position. Now that dealers rely more heavily on customer trades for inventory management, those concerns have diminished and price shading has reportedly become standard practice.

The behavior of small dealers has changed, as well. Since the technology infrastructure required for strong customer relationships is expensive to develop and maintain, many smaller dealers now simply license this technology from larger dealers, a practice known as "white labeling." Some small banks outside of the major trading centers have even begun to withdraw from trading the most liquid currencies, where competition is most intense, focusing instead on trading their own local currency as a service to customers. Small banks traditionally relied almost entirely on profits from customer service, rather than speculative interdealer trading, to fund their trading operations; fortunately, electronic trade processing has allowed any decline in customer service revenues to be matched by declining costs.

Beyond the major dealing banks there are three other providers of foreign exchange 
liquidity: global custodian banks, retail aggregators, and high-frequency traders. Global custody banks provide safekeeping, recording, and transaction services for institutional asset managers, primarily mutual funds, pension funds, endowments, and other funds with low leverage. In 2007 such institutions had custody of about $\$ 100$ trillion assets (Institutional Investor, 2007). Retail aggregators are internet based platforms that enable small individual investors to participate in the foreign exchange market.

Neither retail aggregators nor high-frequency traders existed prior to about 2000. The former take their customers' trades, which are generally under $\$ 100,000$, and aggregate them into the $\$ 1$-million or larger trades favored by large banks. This allows the aggregator to pass on to their customers the small bid-ask spreads of the interdealer market. Some aggregators act as dealers, trading on a principal basis with customers; others act as brokers, trading on an agency basis; some act in both ways. Though retail aggregators commonly allow customers to leverage up to 200 percent, they tightly control their risk by imposing margin requirements and liquidating positions instantaneously when margin calls are not met. The U.S. recently imposed a maximum retail leverage limits of 50 percent. High frequency traders exploit price discrepancies across electronic trading platforms by trading literally at lightning speed. Competition from these very low cost liquidity providers has been a major factor encouraging banks to internalize customer trades.

\section{Liquidity Demanders}

Liquidity demanders in the forex market include corporations, retail investors, and financial institutions. Financial institutions include regional and smaller banks, central banks, highleverage asset managers such as hedge funds and low-level asset managers such as pension funds, endowments, and mutual funds. Regional and smaller banks are often customers of the major banks for trades in the most liquid currency pairs. Central banks of most major developed countries intervene infrequently, though there are notable exceptions including Japan. By contrast, most emerging market central banks intervene actively. The list of apparent 
interveners includes such diverse countries as Hungary, Brazil, Israel, and Vietnam (Nguyen, 2009).

Liquidity demanders vary in the nature of their reliance on the foreign exchange market. Financial customers rely on foreign currencies primarily as a store of value. Corporate customers, by contrast, rely on foreign exchange primarily as a medium of exchange, since they use foreign currencies to buy and sell goods and services and it is not efficient for them to implement the costly risk protections associated with speculative trading (Osler, 2009).

As in most OTC markets, foreign exchange customer market historically had difficulty gaining up-to-date price information about the market. Trades between dealers and customers need not be reported, given the lack of regulation, and interdealer prices were expensive. Market transparency increased dramatically, however, with the advent of electronic trading. Customers can now follow the interdealer prices throughout the day at low cost. On "request for quotes" systems customers can compare quotes from multiple dealers simultaneously. Large institutional customers can even offer liquidity to the market on certain electronic trading platforms, rather than simply demanding liquidity from dealers. The improved transparency has, in turn, brought heightened competition among dealers and reduced bid-ask spreads.

Microstructure research portrays customers as the agents that bring fundamental information to the market, thus beginning the process, known as "price discovery," through which prices reflect underlying fundamentals (this process is discussed in greater depth below). Foreign exchange customers differ in the extent to which they are informed. Dealers generally consider hedge funds to be best informed, which may be because the standard " 2 and 20 " compensation structure ( 2 percent of NAV plus 20 percent of profits) provides such strong incentives to gather market-relevant information. Real money funds tend to focus primarily on own-currency returns to underlying assets and are generally considered by dealers to be relatively uninformed about exchange rates (Taylor and Farstrup, 2006). This lack of focus on 
foreign exchange may help explain the tendency, discussed above, for real-money funds to delegate currency trading to their global custody banks.

Since the advent of retail aggregators around 2000, retail investing has exploded worldwide; it may already represent up to 10 percent of trading (King and Rime, 2010). Research shows that retail currency traders concentrate in the major currencies, generally trade intraday, adopt high leverage, and are generally unprofitable (Heimer and Simon, 2011). The lack of profitability may reflect a lack of market-relevant information (Nolte and Nolte, 2009).

As in equity and bond markets, algorithmic (or "algo") trading has become ubiquitous in the more liquid currency markets. Algo trading involves computer algorithms that execute foreign exchange trades with reference to market conditions; once programmed, they trade without human intervention. Algorithms are often used to divide large trades into smaller individual transactions and space them out over time, thereby reducing execution costs. Another form of algorithmic trading, known as "high frequency trading," was discussed earlier.

\section{ORder Flow ANd EXChange RATES}

Order flow has been a major focus of currency research since it was demonstrated to be a major proximate cause of exchange rate returns (Evans and Lyons, 2002a; Hau, Killeen and Moore, 2002). Order flow is defined as the number of trades in which the buyer was the aggressor minus the number of trades in which the seller was the aggressor. In a limit-order market, the aggressor is the agent placing a market order; in an OTC market the aggressor is the agent requesting a quote. In essence, order flow measures net liquidity demand, since the aggressor is the party demanding liquidity.

The key findings in this area rely on a simple linear regression between returns and order flow for a single currency pair $C$ :

$$
\operatorname{Return}_{t}^{c}=\alpha+\beta^{c} \text { Orderflow }_{t}^{c}+\varepsilon_{t}
$$


The coefficient on order flow is consistently positive at horizons ranging from 1 minute to a few months, implying that a currency appreciates when order flow for that currency is positive. To be more specific, the value of the euro has been estimated to appreciate by an average of 47 basis points per billion euros traded at the 10-minute horizon, 40 basis points at the 1-day horizon, and 20 basis points at the 1-month horizon. Figures for dollar-yen are higher at the 10-minute horizon but otherwise similar. The explanatory power of order flow for returns is substantial, especially when compared to the below-10-percent R-squared common for macro-based exchange rate models. For euro-dollar, the basic order flow regression explains $50 \%$ of 10 minute returns, $46 \%$ of daily returns, and about $20 \%$ of 1 -month returns. Figures are similar for other currencies (Berger et al., 2006).

An expanded version of the basic order flow regression including order flow from multiple currencies has also proved useful:

$$
\operatorname{Return}_{t}^{c}=\alpha+\sum_{C} \beta^{c} \text { Orderflow }_{t}^{c}+\mu_{t}
$$

Evans and Lyons (2002b) find the joint explanatory power for seven currencies against US dollar averages 65 percent, with a maximum of 78 percent, which substantially excees the explanation power of single-currency models.

Though these results suggest that prices move in the direction of net liquidity demand, it is important to consider the possibility that the positive relation actually reflects reverse causality - that dealers buy (sell) in response to price increases (decreases). The relevant studies show that there is definitely feedback trading in this market (Danielsson and Love, 2006; Osler, 2009), but the apparent influence of order flow on returns not only survives the adjustment for such feedback (Evans and Lyons, 2005a) but becomes stronger in some cases (Danielsson and Love, 2006).

The literature focuses on three hypotheses to explain the relation between interdealer order flow and returns: inventory effects, information effects, and liquidity effects. 


\section{Inventory Effects}

To cover their costs, liquidity providers must quote a positive bid-ask spread, meaning they must offer to sell an asset at a price above the price at which they are willing to buy. This very bid-ask spread could thus induce prices to move in the direction of liquidity demand: buyinduced trades would tend to raise prices to the higher ask quote while sell-induced trades would reduce prices to the lower bid quote. In the absence of other influences on exchange rates, however, this effect should be only temporary, since any move up to the ask would soon be followed by a move down to the bid. However, the connection between order flow and exchange rates is substantially permanent. This permanence is suggested by the $20 \%$ explanatory power of order flow regressions at the 1-month horizon cited earlier (Berger, 2006) and by the existence of any effect at the daily horizon, given that exchange rates are wellapproximated by a random walk (Evans and Lyons, 2002a), among other findings.

\section{Information effects}

A permanent effect of order flow on exchange rates could reflect the response of prices to market-relevant information (Lyons, 2001). Suppose, for example, that a speculator expects a soon-to-be released trade balance statistic to be higher than generally expected, which would imply a stronger home currency. When the speculator buys that currency in anticipation of the news, the associated order flow would reveal to dealers that this agent believes the currency is undervalued. As dealers trade on that information it would become progressively embedded in the exchange rate itself.

The relevance of private information for returns was originally identified in theoretical work inspired by equity markets (Kyle, 1985; Glosten and Milgrom, 1985). This early research cannot be adopted wholesale to interpret currency markets, however, since the nature and sources of private information vary across markets. An equity analyst can gain private information by visiting a firm or by comparing the firm's product closely with that of competitors. There is no analogous approach to learning about a currency, other than perhaps eliciting 
secrets about intervention from central bankers. Indeed, most of the macroeconomic information relevant to fundamental currency values, such as export and import figures, are publicly available. Private information about currencies exists, nonetheless, in part because macroeconomic data are always released with a lag. Foreign exchange customers might hold dispersed information about some yet-to-be-announced macro aggregate.

Suppose a corporation purchases more imported inputs because the country is in an economic upswing so demand is strong for its products. A currency dealer observing such behavior among many firms could infer the improving economy (Lyons, 2001), even though each individual corporation might be unaware of the broader economic pattern. When the dealer trades on that information, its trades will lead the information to influence exchange rates (Glosten and Milgrom, 1985; Holden and Subrahmanyam, 1992; Osler et al., 2011). Since the trades reflect fundamental information, the exchange rate move would be lasting.

The trades of financial customers, such as asset managers, will often reflect investor risk perceptions, wealth accumulation, and other fundamental factors. Thus these trades could also unintentionally reveal dispersed macroeconomic information. Hedge funds and other members of the "active trading community" can reveal heterogeneous private information, as well, but their information tends to be actively acquired through intentional research (Harris and Raviv, 1993; Banerjee et al., 2010; Kandel and Pearson, 1995).

There is by now substantial evidence that foreign exchange order flow does carry private information. Evans and Lyons (2005) find that daily customer order flow at Citibank has forecasting power for exchange-rate returns at horizons up to six months. Evans and Lyons (2007) show that Citibank customer order flow has substantial predictive power for future GDP, inflation and money stocks . Ramadorai (2008) shows that State Street Corporation's institutional-investor flows have predictive power, as well.

If customers are asymmetrically informed, then dealers should be asymmetrically informed as well, since each dealer has different customers. Bjønnes et al. (2011) shows that 
larger banks are better informed than smaller banks. This seems logical, since larger dealers have more customers, and dealers themselves support this general idea (Goodhart, 1988; Cheung and Chinn, 2001). Further evidence for information asymmetries across dealers is presented in Moore and Payne (2011).

The existence of information asymmetries among customers raises the question of which customers are best informed. The evidence generally indicates that financial customers are better informed than corporate customers (Fan and Lyons, 2003; Carpenter and Wang 2003; Osler et al., 2011; Bjønnes et al., 2011), and some further evidence suggests that, among financial customers, hedge funds are particularly well-informed (Osler and Vandrovych, 2007). In emerging markets, information asymmetries may exist between domestic and foreign customers. Gereben et al. (2006), who examine the market between Hungarian forints and euros, find that foreign players are better informed than domestic customers. Dealers themselves represent another potential source of information; at least two studies provide evidence that foreign exchange dealers not only aggregate information gathered from customers but also represent an independent source of information (Bjønnes et al., 2011; Moore and Payne, 2011).

Froot and Ramadorai (2005), using a multi-year database of financial flows, find that the positive short-run correlation between financial order flow and return peaks after a few months and then declines, reaching zero at about 300 trading days. Though this suggests that the influence of financial order flow is transitory, it does not undermine the hypothesis that information is key to the link between order flow and returns. Indeed, it is predicted by an exchange rate model that incorporates much of the microstructure evidence developed to date (Osler et al., 2008). The reason is straightforward: investor purchases must inevitably be liquidated, so the influence of order flow associated with the opening of any investor positsion will eventually be reversed when that position is closed. This model also predicts that the longrun effect of corporate order flow should not be zero, since only one side of most normal 
commercial trades involves the foreign exchange market (the other involves direct payment or receipt of a home currency). Overall, the microstructure evidence predicts that financial forces drive exchange rates at short horizons while real-economy forces, such as relative prices, drive exchange rates at long horizons, a prediction that is consistent with much empirical evidence. Microstructure evidence comes from Fan and Lyons (2003). Macroeconomic sources, which are too numerous to list individually, consistently find that PPP primarily influences exchange rates at multi-year horizons while interest rates and financial variables more generally primarily influence exchange rates at far shorter horizons.

\section{Liquidity Effects}

Shleifer (1986) was among the first to propose that demand and supply for financial assets have finite elasticity, a phenomenon referred to in equity research as "downward-sloping demand." In support of this Shleifer showed that some uninformed trading - specifically trading upon the addition of a stock to the S\&P 500 index - generates persistent abnormal equity returns. The relevance of finite demand or supply elasticity is referred to in currency research as a "liquidity effect." The liquidity in question, however, is not the instant liquidity provided by dealers, but instead what is called "overnight" liquidity. Overnight liquidity is needed in the foreign exchange market because individual dealers generally finish the trading day with zero inventory. The dealing community as a whole, therefore, does not provide overnight liquidity. For one set of customers to change its net position over the day, some other set of customers must take the opposite side and hold it at least until the next trading day.

There are two groups whose currency demand or supply could be expected to have finite elasticity. The first is risk-averse investors, who should - in theory, at least - increase demand for any risky asset when its price falls and raises the risk premium (Evans and Lyons, 2002a). There is as yet no evidence that this source of overnight liquidity is influential in currency markets. The absence of evidence could simply reflect the paucity of disaggregated data on financial-customer transactions since some financial agents - most notably technical 
traders - should be insensitive to risk premiums. The other group whose currency demand should have finite elasticity is commercial customers, since a depreciated foreign currency means cheaper imported inputs (higher demand) or a lower realized value from exports priced in foreign currency (lower supply). Commercial customers who do not actively monitor the market intraday can respond sensitively to returns by relying on take-profit orders, which instruct a dealer to buy (sell) a certain amount of a currency when its value falls (rises) to a pre-specified level (Osler, 2003).

The microstructure evidence supports the importance of this second group, commercial customers, as providers of overnight liquidity. One study shows that commercial customer order flow, but not financial order flow, responds to lagged daily returns (Marsh and O'Rourcke, 2005). Another study shows that commercial order flow lags financial order flow intraday but not vice versa (Bjønnes et al., 2005). More broadly, many datasets confirm that commercial (financial) order flow has a negative (positive) contemporaneous relation with returns (Lyons, 2001; Bjonnes et al., 2005; Osler et al., 2011).

\section{BID-AsK SPREAdS}

The provision of instantaneous liquidity is one of the primary purposes of any financial market. A perfectly liquid market is defined as one in which trades can be executed immediately and at zero cost (O'Hara, 1995). While conceptually this seems clear, in practice liquidity is often hard to measure. For small trades there may be little difficulty, since liquidity varies directly with quoted spreads. For large trades, however, the quoted spread may be of little relevance since most of the amount will be executed at prices beyond the quotes. In this case only a part of a large trade can be executed at the best available price; the rest is executed at progressively less attractive prices, with the resulting change in average price referred to as "slippage." Slippage will be determined by depth at the quotes and the shape of the order book. Slippage 
can be minimized by splitting large trades into small individual transactions and spreading these transactions out over time. This suggests that the speed which prices recover to equilibrium values after a transaction, known as "resilience," is also important for liquidity. We focus here on bid-ask spreads as a measure of liquidity, since Fleming (2003), who compares measures of liquidity for practical purposes, concludes that the bid-ask spread is a superior for practical purposes than quote size, trade size, trading volume, and trading frequency.

\section{Interdealer Bid-Ask Spreads}

Standard theory postulates that bid-ask spreads compensate dealers for operating costs (e.g., salaries, facilities, capital); inventory carrying costs; inventory risk; and adverse-selection costs, meaning potential losses from trading with better-informed customers. In equity markets, bidask spreads sometimes provide rents associated with monopolistic or oligopolistic market power (Smidt, 1971; Christie and Schultz, 1994a, 1994b).

Interdealer currency spreads are unlikely to be influenced by monopoly/oligopoly power since the interdealer market has historically been intensely competitive; indeed, dealers state in surveys that market power is not among the major determinants of spreads (e.g., Cheung and Chinn, 2001). Interdealer spreads are also unlikely to be influenced by inventory carrying costs because dealers typically do not hold positions overnight.

Osler et al. (2012) use EBS data for 2003-2006 to show that operating costs, inventory risk, and adverse selection have a significant influence on interdealer spreads in the liquid currency pairs. Operating costs have historically been relatively low in currency markets and they fell even further with the widespread adoption of electronic trading. Trading itself sped up and trade processing became vastly more efficient with the development of straight-through processing (STP), in which a given trade goes from trading to confirmation and settlement entirely electronically. STP speeds the trade processing even while dramatically reducing human error. The associated reduction in costs permitted the narrowing of bid-ask spreads associated with increased transparency, as discussed above. Quoted interdealer spreads in the 
most liquid currency markets, typically on the order of 5 basis points in the 1990s, are now often less than 1 basis point, a development that has effectively reduced the market's tick size.

Theory suggests that inventory risk is driven by current inventory, price volatility, the size of any prospective trade, and the time until the next likely trade (e.g., Stoll, 1978; Rosu, 2008). Since interdealer trading is fast, inexpensive, and anonymous, forex dealers typically maintain inventory close to zero and inventories generally prove insignificant in empirical analysis of dealer behavior (e.g., Bjønnes and Rime, 2005; Osler et al., 2011). Volatility, by contrast, is clearly influential, as it is in equity and bond markets. Daily measures of interdealer spreads move strongly with volatility (Bessembinder, 1993; Hartmann, 1999), an effect that was dramatized by the doubling of spreads on September 11, 2001 (Mende, 2006).

On an intraday basis there are striking contrasts between the behavior of equity and currency spreads. Equity spreads, volume, and volatility all follow what is typically described as an asymmetric $U$-shape across the trading day: they peak when the market opens, decline for a few hours, level off, and then rise modestly until the market closes. Interdealer foreign exchange spreads, by contrast, peak during the overnight hours when trading is lowest and hit their trough around mid-day London time when trading volume and volatility are highest (see Figure 1).

Osler et al. (2012) provide evidence that the intraday pattern of currency spreads is driven by adverse selection and time-to execution. Adverse selection appears to peak overnight, when uninformed customer groups are inactive but the dealing banks have traders available and members of the active trading community remain active through trading algorithms. More broadly, Osler et al. (2012) attribute the difference in behavior between equity and currency bidask spreads to the lack of formal trading hours in foreign exchange. Equity markets are closed for more than half of each 24-hour day, during which time private information accumulates that does not become embedded in prices. When equity markets finally open, therefore, informed agents rush to trade on the accumulated information (Holden and Subrahmanyam, 1992) and adverse selection hits its intraday peak (Madhavan et al., 1997). Thereafter, private information 
arrives sequentially rather than in bulk, so adverse-selection risk, volatility, and trading volume all decline. The liquid forex markets, by contrast, never formally close so trading remains active all day and the price discovery process operates smoothly throughout. The influence of fixed trading hours comes into even clearer focus when we note that interdealer foreign exchange spreads follow an asymmetric U-shape in those few relatively illiquid forex markets with fixed trading hours, (see Menkoff et al. (2010) for the Russian Ruble market and Gau (2005) for the Taipei market).

Adverse selection and inventory risk are also important determinants of interdealer spreads in emerging market currencies, according to evidence presented in Froemmel and Gysegem (2011) for the Hungarian Forint-Euro interbank market. Notably, a dealer's existing inventory position appears to influence bid-ask spreads in this emerging-market currency, which provides a striking contrast with the insignificance of inventories for the most liquid currencies cited above. Froemmel and Gysegem suggest that inventory is more important for this relatively illiquid currency because the low frequency of trades raises waiting times between trades.

\section{Customer Bid-Ask Spreads}

Spreads in the customer tier of the foreign exchange market behave quite differently from interdealer spreads, a contrast that is most apparent in cross-sectional analysis. Osler et al. (2011), Ding (2009), and Rietz et al. (2009) show that customer bid-ask spreads move inversely with trade size. Osler et al. (2011) and Rietz et al. (2009) also show that financial customers are charged smaller spreads than commercial customers for trades of a given size. The reverse of these patterns would be expected if adverse selection, waiting time, or inventory effects dominated customer spreads as they do interdealer spreads.

At least three factors can explain the cross-sectional variation of foreign exchange customer spreads. Fixed operating costs can explain the inverse relation between customer spreads and trade size, since a fixed cost can be easily covered by small spread a larger trade. "Strategic dealing" and "market power," can explain why commercial customers pay wider 
spreads than financial customers. Strategic dealers manipulate the rate of information arrival to their own advantage. In the two-tiered foreign exchange market, dealers can benefit from customer information when they trade with other dealers. It can therefore be rational for dealers to maximize trades with informed customers, which they can achieve by quoting such customers relatively narrow spreads. Consistent with this, Ramadorai (2008) finds that asset managers with the greatest skill in predicting exchange-rate returns pay the smallest spreads.

Customers with private information can be viewed as having a kind of instantaneous market power over their dealers, since dealers are anxious to learn whether they are buying or selling. This allows such customers to extract narrower spreads, and the traders at informed firms often face strong incentives to do so. Dealers have their own source of market power in their up-to-the-minute familiarity with market conditions. As discussed earlier, corporate customers generally know little market-relevant private information and the smallest commercial customers - say, a tiny spice importing firm - are often uninformed about basic market features like a normal bid-ask spread or current volatility. In some OTC markets, like the US municipal bond market, a lack of information about market conditions is associated with a lack of market transparency (Green et al., 2007). This is no longer the case in foreign exchange, but small corporate firms could still be relatively uninformed since they cannot afford to devote resources to monitoring the foreign exchange market and timing trades. Further, they typically provide their employees no incentives to minimize forex execution costs. Rietz et al. (2009) show empirically that financial customers have greater market power than commercial customers relative to their foreign exchange dealers.

\section{Custody Spreads}

Like regular foreign exchange dealers, custody-bank dealers trade currencies on a principal basis and cover their inventory positions with other dealers. (A few of the largest custody banks also serve as market makers to the broader foreign exchange community.) The trading process for most custody-bank trades differs from that of standard OTC trades, however. Typically, a 
custody client does not speak directly with the custodial dealer but instead speaks with its "fund accountant," who forwards the trading instruction to the dealer. Since the dealer first covers his position in the interdealer market and then sets the price at which he trades with the customer, the dealer is not exposed to either inventory risk or adverse selection.

Notably, transparency is minimal for custodial clients, who only learn traded prices, not bid-ask spreads, and only receive that limited information a few days or weeks after the trade. Osler et al. (2011) provide evidence that this lack of transparency has a big effect on the bid-ask spreads paid by custodial customers. Their examination of the complete foreign exchange trading record of a mid-sized global custody bank in 2006, indicates that the custodial mark-up of prices relative to the interdealer price is roughly 20 basis points on standard trades. By contrast, the mark-up is only about 3 basis points when clients call the custody-bank traders directly, thereby gaining full information about execution costs. Osler et al. also provide evidence that custodial dealers protect uncertainty about their mark-ups.

\section{Price Discovery}

The price discovery process most widely discussed in the literature is based on equity-market research highlighting the importance of adverse selection. To avoid ex-post regret, dealers incorporate a potential trade's information directly into the quoted price, which implies they must quote a bid-ask spread. As more and more customers trade on a given piece of information, the price moves progressively closer to its full-information value (Glosten and Milgrom, 1985; Holden and Subrahmanyam, 1992).

This price discovery mechanism cannot apply directly to the foreign exchange market, since the best-informed customers pay narrower spreads while regret-free pricing implies the opposite. Osler et al. (2011) propose an alternative price discovery mechanism relevant to the foreign exchange market. They note that when a dealer offloads inventory after a customer 
trade he faces a familiar trade-off: an aggressive trade - such as a market order - provides speedy execution at the cost of the bid-ask spread, while a passive trade - such as a limit order - provides uncertain execution at an uncertain time but earns the bid-ask spread if executed. This trade-off implies that a dealer should be more likely to make aggressive trades after trading with informed customers than after trading with uninformed customers. Aggressive trades after trades with informed customers move the price in the direction implied by the customer's information: upward (downward) after a customer purchase (sale).

In support of this proposed price discovery mechanism, Osler et al. find that the likelihood of an interbank market order is higher after trades that are relatively likely to carry information, specifically financial-customer trades and large trades. This proposed price discovery mechanism is also supported by other evidence including: Rime et al.'s (2010) finding that interdealer order flow has strong predictive power for upcoming macro statistical releases; Phylaktis and Chen's (2010) finding that the top trading banks dominate price discovery in the interdealer market; and Bjonnes et al. 's (2011) finding that dealers with the most informed customers are relatively likely to trade aggressively. This mechanism is also consistent with the stylized fact, reported above, that financial order flow and dealer order flow are positively related to contemporaneous returns while commercial order flow is not.

\section{VOLATILITY}

Evidence shows that asset-price volatility is a fairly persistent process, and exchange-rate volatility conforms to this regularity. Researchers have tended to assume that movements in volatility are driven by order flow which, in turn, is driven by the arrival of new information. If so, exchange rate volatility in a given part of the world would be a home-grown affair. Foreign exchange microstructure research has tested this "heat wave" hypothesis against the alternative "meteor shower" hypothesis that volatility in one part of the world is heavily influenced by volatility elsewhere. Engle et al. (1990) provided the first evidence, subsequently confirmed, that 
volatility surges come in waves that move around the planet, consistent with the "meteor shower" hypothesis. One could similarly inquire about how volatility in one exchange rate influences contemporaneous volatility in other exchange rates. Bubak et al. (2011), who examine the euro-dollar rate and exchange rates among central European currencies, find that daily realized volatility of a given exchange rate depends significantly on the lagged realized volatility of other exchange rates as well as its own lags.

Currency microstructure research has also delved into the sources of volatility persistence. Berger et al. (2006) analyze extensive, highly detailed interdealer trading data using a simple model based on Kyle's (1985) depiction of returns as a linear function of order flow. They postulate, more specifically, that realized volatility $\left(R V_{t}\right)$ is determined by the product of squared order flow $\left(O F_{t}^{2}\right)$ and the squared sensitivity of returns to order flow $\left(\lambda_{t}\right)$ :

$$
R V_{t}=\lambda_{t}^{2} O F_{t}^{2}+\eta_{t}
$$

Here, $\eta_{t}$ is the residual. Under the traditional assumption that volatility derives from the arrival of new information, changes in order flow would dominate changes in volatility. Berger et al. (2006) find that order flow does dominate at short horizons, but that low-frequency movements in volatility are primarily driven by shifts in the price impact of order flow.

\section{SUMmARY AND CONCLUSIONS}

Currency market microstructure research has by now generated an extensive body of empirical findings that paint a fascinating, coherent picture of the foreign exchange market. It shows, importantly, this market differs from equity and bond markets in a number of important dimensions. These include: the existence and role of the interdealer market; the nature and sources of private information; the cross-sectional determinants of customer bid-ask spreads, the intraday behavior of interdealer bid-ask spreads; and the price discovery process. Since the 
foreign exchange market is changing rapidly, new questions are constantly emerging to fuel ongoing research.

The research on currency microeconomics has important implications for exchange-rate modeling. Given the central role of corporate traders in providing overnight liquidity, models with rigorous microfoundations must include such agents. Models will need to focus on flows, rather than stock investment holdings, because exchange rates only respond to currency-market flows and only about half of corporate currency payments actually move through the market. Finally, models will need to incorporate the fact that any investment is ultimately liquidated, so that most financial flows are ultimately reversed. This has the crucial implication that financial flows have only limited long-run influence on rates, leaving corporate flows to dominate in the long-run. 


\section{REFERENCES}

Banerjee, Snehal, and Ilan Kremer. 2010. “Disagreement and Learning: Dynamic Patterns of Trade." Journal of Finance 65:4, 1269-1302.

Bank for International Settlement. 2010. Triennial Central Bank Survey of Foreign Exchange and Derivatives Market Activity in April 2010. Publication of the Monetary and Economics Department, Bank for International Settlement.

Bessembinder, Hendrik. 1993. "Bid-Ask Spreads in the Interbank Foreign Exchange Markets." Journal of Financial Economics 35:3, 317-348.

Berger, Helge, Ehrmann, Michael, and Marcel Fratzscher. 2006. "Forecasting ECB Monetary Policy: Accuracy is a Matter of Geography." International Monetary Fund Working Paper 578.

Berger, David, Chaboud, Alain, Hjalmarsson, Erik, and Edward Howorka. 2006. "What Drives Volatility Persistence in the Foreign Exchange Market?" International Finance Discussion Papers 862, Board of Governors of the Federal Reserve System.

Bjønnes, Høidal G., and Dagfinn Rime. 2005. “Dealer Behavior and Trading Systems in Foreign Exchange Markets," Journal of Financial Economics 75:3, 571-605.

Bjønnes, Høidal G., Rime, Dagfinn, and Haakon O. A. Solheim. 2005. "Liquidity Provision in the Overnight Foreign Exchange Market," Journal of International Money and Finance 24:2, 175-196.

Bjønnes, Geir, Osler, Carol L., and Dagfinn Rime. 2011. "Sources of Information Advantage in the Interbank Foreign Exchange Market." Mimeo.

Bubák, Vít, Kocenda, Evzen, and Zikes, Filip. 2011. "Volatility Transmission in Emerging European Foreign Exchange Markets." Journal of Banking \& Finance 35:11, 2829-2841. CNN Money, January 19, 2012, money.cnn.com/2012/01/19/markets/trading_volume/index.htm. 
Canales-Kriljenko, Jorge I., 2004. “Foreign Exchange Market in Selected Developing and Transition Economies: Evidence from a Survey." IMF Working Paper 04/04, International Monetary Fund.

Carpenter, Andrew, and Wang Jianxin. 2003. "Sources of Private Information in FX Trading." Mimeo, University of New South Wales.

Carter, David, and Betty J. Simkins. 2002. “Do Markets React Rationally? The Effect of the September $11^{\text {th }}$ Tragedy on Airline Stock Returns." Working Paper. Oklahoma State University.

Cheung, Yinwong, and Menzie D. Chinn. 2001. "Currency Traders and Exchange Rate Dynamics: A Survey of the US Market." Journal of International Money and Finance 20:4, 439-471.

Christie, William G., Harris, Jeffrey H., and Paul H. Schutz. 1994. "Why Did NASDAQ Market Makers Stop Avoiding Odd-Eighth Quotes?" Journal of Finance 49:5, 1841-1860.

Christie, William G., and Paul, H. Schultz. 1994. "Why Do NASDAQ Market Makers Avoid Odd-Eighth Quotes?” Journal of Finance 49:5, 1813-1840.

Csavas, Csaba, and Rezso Szabo. 2010. “Determinants of Hungarian Forint FX Swap Spreads After the Lehman Crisis." Working Paper, Central Bank of Hungary.

Danielsson, Jon, and Ryan Love. 2006. "Feedback Trading." International Journal of Finance and Economics 11: 1, 35-53.

Demsetz, Harold. 1968. “The Cost of Transacting." Quarterly Journal of Economics 82:1, 33-53.

Ding, Liang. 2009. "Bid-Ask Spread and Order Size in the Foreign Exchange Market: An Empirical Investigation." International Journal of Finance and Economics 14: 1, 98-105. Easley, David, and Maureen O'Hara. 1987. “Price, Trade Size, and Information in Securities Markets." Journal of Financial Economics 19:1, 69-90. 
Engle, Robert F., Takatoshi Ito, and Wen-Ling Lin. 1990. "Meteor Showers or Heat Waves? Heteroskedastic Intra-daily Volatility in the Foreign Exchange Market." Econometrica 58: 3, $525-542$.

Evans, Martin D.D., and Richard K. Lyons. 2002a. "Order Flow and Exchange Rate Dynamics." Journal of Political Economy 110:1, 170-180.

Evans, Martin D.D., and Richard K. Lyons. 2002b. "Information Integration and FX Trading," Journal of International Money and Finance 21:6, 807-831.

Evans, Martin D.D., and Richard K. Lyons. 2005. "Do Currency Markets Absorb News Quickly?" Journal of International Money and Finance 24:2, 197-217.

Evans, Martin D. D. and Richard K. Lyons. 2007. "Exchange Rate Fundamentals and Order Flow." National Bureau of Economic Research Working Paper 13151.

Fan, Mintao and Richard K. Lyons, 2003. Customer Trades and Extreme Events in Foreign Exchange. In Paul Mizen (ed.), Monetary History, Exchange Rates and Financial Markets: Essays in Honour of Charles Goodhart, 160-179. Northampton: Edward Elgar.

Fleming, Michael J., 2003. "Measuring Treasury Market Liquidity," Federal Reserve Bank of New York Economic Policy Review 9:3, 83-108.

Froot, Kenneth A., and Ramadorai, Tarun. 2005. "Currency Returns, Intrinsic Value, and Institutional Investor Flows," Journal of Finance 60:3, 1535-1566.

Froemmel, Michael, and Frederick V. Gysegem. 2011. "Spread Components in the Hungarian Forint-Euro Market." Working Papers 11/709, Faculty of Economics and Business Administration, Ghent University.

Gau, Yinfeng. 2005. "Intraday volatility in the Taipei FX Market." Pacific-Basin Finance Journal $13: 4,471-487$. 
Gereben, Aron, Gyomai, Gyorgy, and Norbert M. Kiss. 2006. "Customer Order Flow, Information and Liquidity on the Hungarian Foreign Exchange Market." MNB Working Papers, Central Bank of Hungary.

Glosten, Lawrence R., and Paul R. Milgrom. 1985. "Bid, Ask and Transaction Prices in a Specialist Market with Heterogeneously Informed Traders." Journal of Financial Economics $14: 1,71-100$.

Glosten, Lawrence R. 1989. “Insider Trading, Liquidity, and the Role of the Monopolist Specialist." Journal of Business 62:2, 211-235.

Goodhart, Charles. 1988. "The Foreign Exchange Market: A Random Walk with a Dragging Anchor." Economica 55:220, 437-460.

Green, Richard C., Burton Hollifield, and Norman Schurhoff. 2007. "Financial Intermediation and the Costs of Trading in an Opaque Market." Review of Financial Studies 20:2, 275-314.

Harris, Milton, and Artur Raviv. 1993. "Differences of Opinion Make a Horse Race." Review of Financial Studies 6:3, 473-506.

Hartmann, Philipp. 1999. "Trading Volumes and Transaction Costs in the Foreign Exchange Market: Evidence from Daily Dollar-Yen Spot Data." Journal of Banking and Finance 23:5, 801-824.

Hau, Harald, William Killeen, and Michael Moore. 2002., "How has the Euro Changed the Foreign Exchange Market?" Economic Policy 17:34, 151-177.

Heimer, Rawley Z., and David Simon. 2011. “Facebook Finance: How Social Interaction Propagates Active Investing." Working Paper, Brandeis University, International Business School.

Holden, Craig W., and Avanidhar Subrahmanyam. 1992. "Long-Lived Private Information and Imperfect Competition." Journal of Finance 47:1, 247-270.

Huang Roger D., and Hans R. Stoll. 1997. "The Components of the Bid-Ask Spread: A General Approach." Review of Financial Studies 10:4, 995-1034. 
Institutional Investor Magazine. 2007. "Global Custody Rankings."

http://www.iimagazinerankings.com/globalcustody/GlobalCustodyRanking.asp

Kandel, Eugene, and Neil D. Pearson. 1995. "Differential Interpretation of Public Signals and

Trade in Speculative Markets." Journal of Political Economy 103:4, 831 - 872.

King, R. Michael, and Dagfinn Rime. 2010. "The \$4 Trillion Question: What Explains FX Growth Since 2007?" Bank for International Settlements Quarterly Review.

King, R. Michael, Carol Osler, and Dagfinn Rime. 2012. "Foreign Exchange Market Structure, Players, and Evolution.” In: James, J., Marsh, I., Sarno, L. (eds), Handbook of Exchange Rates. New York: Wiley and Sons.

Kyle, Albert S. 1985. "Continuous Auctions and Insider Trading." Econometrica 53:6, 1315-35. Lechner, Sandra, and Ingmar Nolte. 2009. "Customer Trading in the Foreign Exchange Market: Empirical Evidence from an Internet Trading Platform. "Working Paper, Warwick Business School.

Linnainmaa, Juhani, and loanid Rosu. 2008. "Time Series Determinants of Liquidity in a Limit Order Market." AFA 2009 San Francisco Meetings Paper.

Liu, Huan. 2005. Asia Times October. 27 (www.atimes.com/globaleconomy/GJ27Dj01.html) Lyons, Richard K. 2001. The Microstructure Approach to Exchange Rates. Cambridge and London: MIT Press.

Lyons, Richard K. 2003. "Explaining and Forecasting Exchange Rates with Order Flows." Economie Internationale 4:96, 107-127.

Lyons, Richard K. 2001. The Microstructure Approach to Exchange Rates. Cambridge and London: MIT Press.

Madhavan, Ananth, Richardson, Matthew and Mark Roomans. 1997. "Why Do Security Prices Change? A Transaction-Level Analysis of NYSE Stocks." Review of Financial Studies 10:4, 1035-1064. 
Marsh W. Marsh, and Ceire O’Rourke. 2005. “Customer Order Flow and Exchange Rate Movements: Is There Really Information Content?" Working Paper, Cass Business School. Mende, Alexander. 2006. "09/11 and the USD/EUR Exchange Market." Applied Financial Economics 16:3, 213-222.

Menkhoff, Lucas, Osler, Carol L., and Schmeling M. 2010. “Order Submission Strategies under Asymmetric Information." Journal of Banking and Finance 34:11, 2665-2677.

Mizarch, Bruce, and Yoichi Otsubo. 2001. "The Market Microstructure of the European Climate Exchange." Working Paper 201005, Rutgers University.

Moore, Michael J., and Richard Payne. 2011. "On the Sources of Private Information in FX Markets." Journal of Banking and Finance 35:5, 1250-1262.

Nguyen, Tran P. 2009. “ Implications of Exchange Rate Policy for Foreign Exchange Market Development: Vietnam, 1985-2009." Thesis, Griffith University.

O’Hara, Maureen. 1995. Market Microstructure Theory. Cambridge: Blackwell.

Osler, Carol L. 2003. "Currency Orders and Exchange-Rate Dynamics: Explaining the Success of Technical Analysis." Journal of Finance 58:5, 1791-1819.

Osler, Carol L., and Vitaliy Vandrovych. 2007. "Hedge Funds and the Origins of Private Information in the Foreign Exchange Market." Brandeis University Working Paper.

Osler, Carol L., Carlson, John A., and Christian M. Dahl. 2008. "Short-Run Exchange-Rate Dynamics: Theory and Evidence." Working Paper 2008-01, School of Economics and Management, University of Aarhus.

Osler, Carol L., Alexander Mende, and Lukas Menkhoff. 2011. "Price Discovery in Currency Markets." Journal of International Money and Finance 30:8,1696-1718.

Osler, Carol L., Savaser, Tanseli, and Thang Nguyen. 2011. "Asymmetric Information and the Foreign Exchange Trades of Global Custody Banks". Working Paper, Brandeis University Osler, Carol L., Sherman, Rimma, and David Simon. 2012. “Determinants of Intraday Spreads in the Interdealer Foreign Exchange Market." Mimeo, Brandeis University. 
Payne, Richard, and Love, Ryan. 2008. "Macroeconomic News, Order Flows, and Exchange Rate." Journal of Financial and Quantitative Analysis 43:2, 467-488.

Phylaktis, Kate, and Long Chen. 2010. "Asymmetric Information, Price Discovery, and Macroeconomic Announcements in FX Markets: Do Top Trading Banks Know More?" International Journal of Finance and Economics 15:3, 228-246.

Ramadorai, Tarun. 2008. "What Determines Transaction Costs in Foreign Exchange Markets?" International Journal of Finance and Economics, 13:1, 14-25.

Reitz, Stefan, Markus Schmidt, and Mark Taylor. 2009. "Financial Intermediation and the Role of Price Discrimination in a Two-Tier Market." presented at the Fifth Annual Central Bank Workshop on the Microstructure of Financial Markets, Zurich, Switzerland, October 9, 2009.

Rime, Dagfinn, Lucio Sarno, and Elvira Sojli. 2010. "Exchange Rate Forecasting, Order Flow and Macroeconomic Information." Journal of International Economics 80: 1, 72-88.

Rosu, Ioanid. 2008. "Liquidity and Information in Order Driven Markets." Working Paper, University of Chicago.

Shleifer, Andrei. 1986. "Do Demand Curves for Stocks Slope Down?” Journal of Finance 41:3, 579-590.

Smidt, Seymour. 1971. "Which Road to an Efficient Stock Market: Free Competition or Regulated Monopoly?" Financial Analysts Journal 27:5. 18-20.

Stoll, Huang. 1978. "The Supply of Dealer Services in Security Markets." Journal of Finance 33:4, 1133-1151.

Taylor, Andrew, and Farstrup, Adam. 2006. Active Currency Management: Arguments, Considerations, and Performance for Institutional Investors. CRA RogersCasey International Equity Research: Darien, Connecticut.

Tkatch, Isabel, and Kandel, Eugene. 2008. "Demand for the Immediacy of Execution: Time is Money." Working Paper, Georgia State University. 
Wooldridge, Philip, and Tsuyuguchi, Yosuke. 2008. "The evolution of trading activity in Asian foreign exchange markets." Working Paper, Monetary and Economics Department, Bank for International Settlement. 


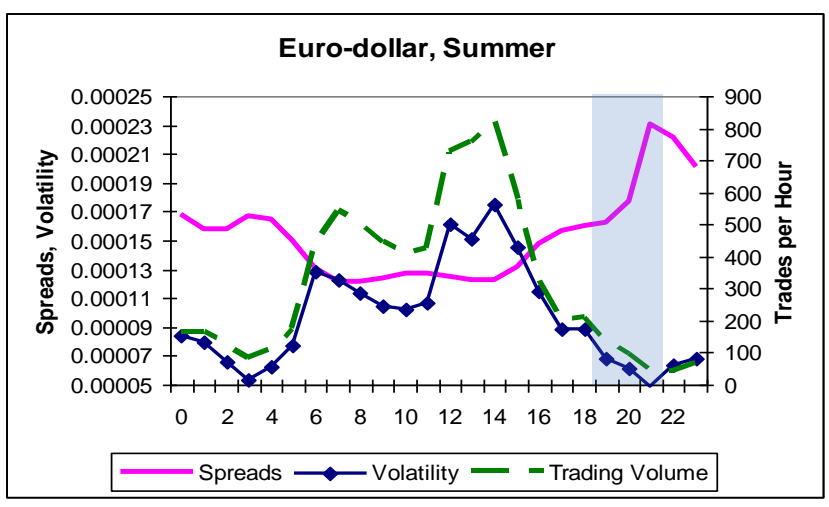

Figure 1: Transaction volumes, volatility, and bid-ask spreads in the foreign exchange interdealer market. Data for the period December 28, 2002 through March 3, 2006 come from EBS. Calculations are separately for summer, which stretches from April through October, because Japan does not adopt daylight savings time. The patterns differ only slightly for winter. Volatility scaled to match spreads. Shaded area indicates the market's "overnight" period of light trading. 


\section{Discussion Questions}

1. Contrast the foreign exchange market's two-tiered structure with the one-tier structure assumed in classic microstructure papers including Kyle (1985) and Glosten and Milgrom (1985). Consider not just the number of tiers, but also the way dealers view informed customers.

In the classic microstructure models, dealers trade with customers but not with each other. In foreign exchange, by contrast, dealers trade with customers and also with each other. In classic microstructure models, dealers take the extent of informed customer business to be exogenous, while in foreign exchange, dealers attempt to maximize such business.

2. How do the key factors driving customer and interdealer bid-ask spreads differ between the customer and interdealer markets?

In the interdealer market the key factors beyond operating costs are adverse selection, inventory risk and volatility, and the duration between trades. In the customer market, adverse selection does not influence spreads: rather than attempting to protect themselves from informed customers, dealers attempt to maximize their trades with such customers. The key drivers of customer spreads beyond operating costs therefore include strategic dealing and market negotiating power.

3. Which foreign exchange market participants are most and least likely to be informed? Why?

Corporate customers are generally not well informed because they rely on foreign currencies primarily as a medium of exchange, so there is little incentive to gather information. Financial customers are often informed which is logical since they rely on foreign currencies as a store of value. Among financial customers, hedge funds seem to 
be best informed which may reflect the strong incentives to amass profits faced by hedge fund managers. Dealers also tend to be informed, with bigger dealers better informed than smaller dealers. Dealers are informed in part because they aggregate dispersed information reflected in the trades of their customers. Dealers also bring their own independent information to the market.

4. According to the text, electronic trading brought a dramatic narrowing of bid-ask spreads. How was this possible, given that the market was already intensely competitive?

Electronic trading also brought a dramatic lowering of costs through the introduction of straight through processing (STP). As human involvement disappeared from the processes of confirmation and settlement, errors decreased and costs tumbled. Electronic trading also brought swollen trading volumes, and thus lower costs per trade, as retail, algorithmic, and high-frequency trading all exploded.

5. According to research cited in the paper, large foreign exchange dealing banks are better informed than small dealing banks, which implies that large banks tend to make money when trading against small banks. How could this be an equilibrium - wouldn't small banks rationally leave the market?

If banks relied exclusively on speculative profits from interbank trading to support their dealing operations, then it would indeed be rational for small banks to exit the market to avoid being picked off by better informed banks. Large banks have historically relied heavily on speculative profits, though this reliance has declined in recent years. Small banks never relied heavily on speculative profits to support dealing operations. Instead they rely primarily on returns from servicing customers - that is, on the bid-ask spreads associated with customer trades. 


\section{Biographies}

Carol Osler's research focuses on currency trading and technical analysis. Recent publications also concern sources and effects of imperfect rationality in financial markets, focusing on overconfidence and illusory correlations. Osler is Program Director for the Brandeis University Master of Arts in International Economics and Finance. At

Brandeis she teaches market microstructure, international macroeconomics, and central banking.

Xuhang Wang

Xuhang Wang recently received a Master of Arts in International Economics and Finance from Brandeis International Business School, with a concentration in Finance and substantial training in econometrics. She also holds a Bachelors degree in Business Administration from Zhejiang University. 